\title{
Enzyme therapy for Fabry patients in jeopardy
}

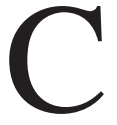

anadians with Fabry disease face an uncertain future because an unusual government-and-industry-funded clinical trial, which provides access to a $\$ 300000$ therapy per patient annually, is in jeopardy. "It is up in the air nobody knows what is happening for patients," says Ed Koning, president of the Canadian Fabry Association.

The federal government will not extend its funding for the Canadian Fabry Disease Initiative Enzyme Replacement Therapy Study past Sept. 30, Health Canada spokesperson Gary Holub confirmed to the CMAJ.

Without more federal money, it is unclear whether the 10-year trial can continue, says Dr. Michael West, principal investigator and physician at the Queen Elizabeth II Health Sciences Centre in Halifax, Nova Scotia.

Treatment access is now in doubt for many patients with the inherited genetic condition, in which a deficiency of the enzyme alpha galactosidase A causes a buildup for a glycolipid in blood vessels, other tissues and organs, impairing their function. "Cutting 130 patients off therapy will be a big problem. ... We want to avoid the chaos that might ensue," West says.

The phase 4 (postmarket approval) trial was announced in 2006, but did not begin enlisting participants until 2007. The federal government contributed $\$ 34.6$ million over three years for the study, with the money administered through the Canadian Institutes for Health Research, which is not a trial funder.

Koning, who lives in Edmonton, Alberta, and receives enzyme replacement therapy through the study, says he has "lots of questions about how the federal government can support a study and then after three years not want any part of it."

An estimated 250 Canadians have Fabry disease, which is classified as a rare or orphan disease because of its low prevalence internationally.
As well as providing therapy to people who meet clinical treatment guideline criteria, the trial is designed to assess the relative usefulness of agalsidase beta and agalsidase alfa, the approved enzyme replacement therapies in Canada.

Manufacturers GenzymeCanada Inc. and Shire Human Genetics Inc., along with Health Canada and provincial and territorial governments, jointly provided $\$ 100$ million for the first three years of the trial, according to a 2006 presentation made when the study was announced.

Negotiations are still underway about whether the trial can continue, provincial spokespersons told CMAJ.

Health Canada approved the expensive therapies for marketing in 2004, but the following year, the Common Drug Review recommended provinces not cover the treatments because of cost and limited evidence of clinical effectiveness.

Health Canada met its commitment to participate in a three-year study, Holub stated in an email. "It was understood from the outset that the funding agreement was, and remains, time-limited to three years and is nonrenewable."

Holub added that after the initial three years, it was expected the study would provide "a new body of information to support jurisdictions' coverage decisions." But Judy McPhee, director of pharmaceutical services for Nova Scotia's department of health, says it was always acknowledged that the study would take longer "especially with such a small cohort of patients."

The study, which is not yet fully enrolled, has not provided enough information to support a decision by Nova Scotia to fund the therapy under its public drug plan, she says. "We don't want to fund a drug if we don't know at the end of the day what it does."

Nova Scotia has the largest cohort of people with Fabry disease in the world, McPhee says. Thirty-six Nova Scotians receive enzyme replacement therapy through the trial and another 200 are in a separate trial cohort com-

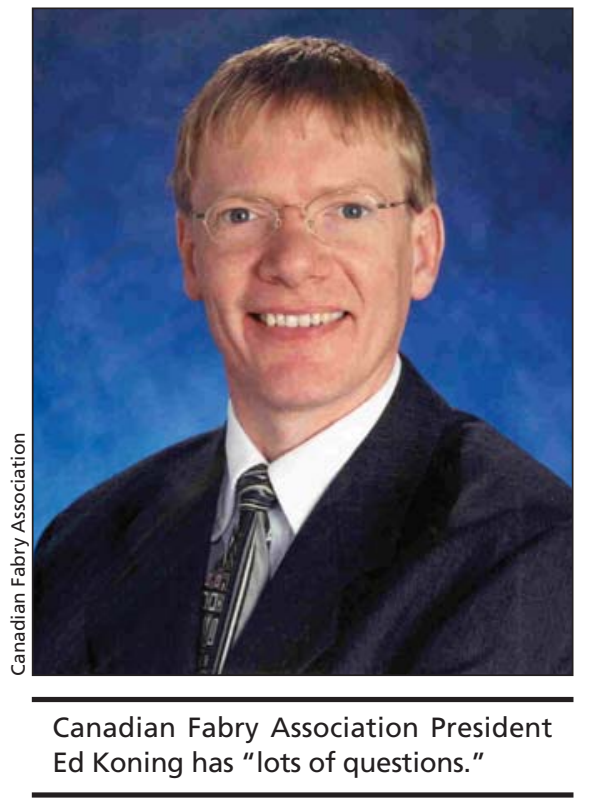

prised of people with a milder form of the disease who do not meet Canadian guideline criteria for treatment.

To date, the only public information about the trial's progress — posted on the website of the Canadian Institutes of Health Research - concerns the 2006/7 fiscal year. "I question how the federal government can make a decision based on only a one-year report," Koning says.

While Health Canada has made no official announcement to its provincial government cofunders about its decision not to renew funding, the provinces have become aware of the cancellation, says McPhee.

Ontario "is interested in continuing the work" on Fabry's disease but as negotiations are ongoing, "is not in a position to discuss any details at this time," provincial Ministry of Health and Long-Term Care spokesperson Andrew Morrison stated in an email. — Ann Silversides, CMAJ

DOI:10.1503/cmaj.109-3013

A related article, "Fabry trial set to answer political problem," is published at www.cmaj.ca 